\title{
Effect of Coastal Waves on Hydrodynamics in One-Inlet Coastal Nador Lagoon, Morocco
}

\author{
Jeyar Mohammed, Elmiloud Chaabelasri, and Najim Salhi \\ LME, Faculté des Sciences, Université Mohammed Premier, 60000 Oujda, Morocco \\ Correspondence should be addressed to Elmiloud Chaabelasri; chaabelasri@gmail.com
}

Received 15 September 2015; Revised 15 November 2015; Accepted 26 November 2015

Academic Editor: Agostino Bruzzone

Copyright ( 2015 Jeyar Mohammed et al. This is an open access article distributed under the Creative Commons Attribution License, which permits unrestricted use, distribution, and reproduction in any medium, provided the original work is properly cited.

\begin{abstract}
Nador lagoon is a coastal system connected to the sea through a narrow and shallow inlet; understanding its hydraulic performance is required for its design and operation. This paper investigates the hydrodynamic impacts of the whole lagoon due to tidal waves using a numerical approach. In this study we use a two-dimensional, depth-averaged hydrodynamic model based on so-called shallow water equations solved within triangular mesh by a developed efficient finite volume method. The method was calibrated and validated against observed data and applied to analyze and predict water levels, tidal currents, and wind effects within the lagoon. Two typical idealized scenarios were investigated: tide only and tide with wind forcing. The predicted sea surface elevations and current speeds have been presented during a typical tidal period and show correct physics in different scenarios.
\end{abstract}

\section{Introduction}

An understanding of the physical oceanography of coastal areas provides a foundation for the study of processes such as hydrodynamics, as well as a basis for effective management of the coastal zone. Integrated water management of endangered coastal areas could be able to restore their ecosystems. Numerical models have been developed and applied to coastal areas, in order to simulate hydrodynamic and environmental processes. These models constitute an administrative tool for decision makers in order to apply the right measures to restore the endangered coastal environments.

Coastal lagoons are areas of shallow, coastal water, wholly or partially separated from the sea by sandbanks, shingle, or, less frequently, rocks. Lagoons show a wide range of geographical and ecological variations. The most important of them in Moroccan coasts is Nador lagoon.

Nador lagoon is located on eastern coast; recently, it has been the subject of many investigations on water quality, currents, flora, fauna, fishing, and aquaculture $[1,2]$. Most of these studies deal with the environmental aspects of the lagoon such as biological [3] and geochemical impacts [4]. However, to the best of our knowledge, there are no research studies on the modelling of hydrodynamics in the Nador lagoon.

In the literature there are some examples of hydrodynamic estimation in coastal lagoon, among others; Brenon et al. [5] determine the effects of tidal influenced hydrodynamics on the water circulation in the Ebrie lagoon using a vertically averaged two-dimensional model and present case tests that explore the effects of trade winds and of large river discharges; Ferrarin et al. [6] develop an application of a 2D finite element model to the lagoons of Marano and Grado simulating the current regime and the salinity distribution in order to derive a hydraulic regime-based zonation scheme. Recently, Serrano et al. [7] describe the tidal hydrodynamics in a coastal lagoon with two inlets, using a two-dimensional numerical model, calibrated with records of sea levels and tidal currents; their model is applied to study the impact and changes of hydraulic regime in the presence of two efficient inlets.

The aim of this paper is the application of a developed 2D finite volume method to the Nador lagoon, based on the well-established shallow water system including bathymetric forces, Coriolis effects, friction terms, and eddy-diffusion stresses, simulating the impact of wind and tidal waves on the hydrodynamics circulation in Nador lagoon; here the flow 


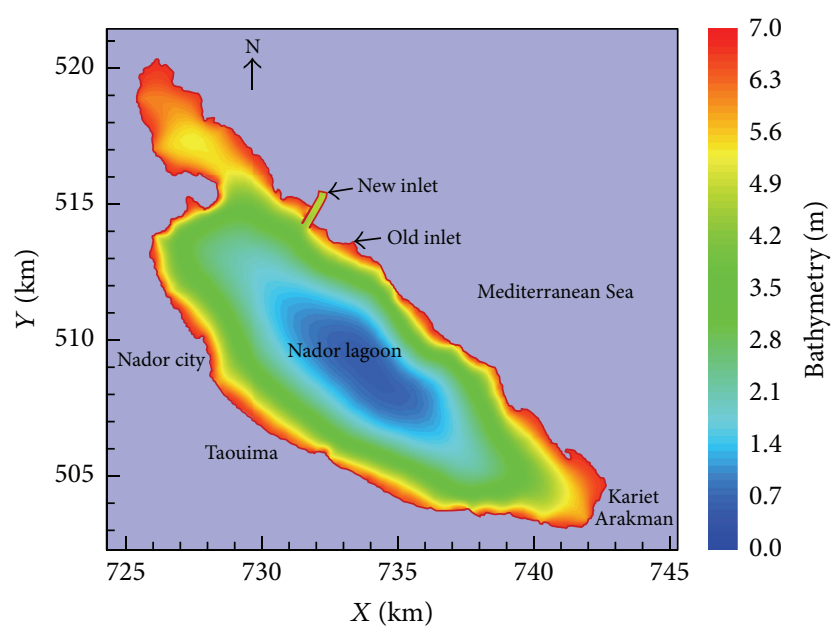

FIGURE 1: Location and bathymetry of the Nador lagoon study area.

is forced by the components of semidiurnal tidal at one real inlet. Recently, the same model has been widely used as shown, for example, in Lovato et al. [8] and Panda et al. [9]. The calibration, followed by validation, of the hydraulic model is the first step of its use. It is to simulate a given period and to compare the outputs of the model with observation by adjusting the Manning coefficient in numerical model. For model calibration, numerical simulation of water level throughout lagoon has been made during the period of May 2014; good agreement is obtained between the water levels and simulated ones. Circulations of the whole basin are then investigated with different conditions of tidal flow at inlet and wind.

\section{Material and Method}

2.1. Description of the System. The Nador lagoon is the second lagoon complex of northern Africa $\left(115 \mathrm{~km}^{2}\right)$, the broadest paralic environment of Morocco, and the only one located along the Mediterranean coast of this country. It comprises a broad area bounded to the northwest by the Beni-Ensar city, to the southeast by the village of Kariat Arekmane, and to the southwest by the northern extremity of the BouAreg plain (Figure 1). This lagoon is protected by northwest and southeast elongated sandy spit ( $25 \mathrm{~km}$ length), with an average width between $300 \mathrm{~m}$ and $400 \mathrm{~m}(2 \mathrm{~km}$ near the southeastern corner) and a small height less than $8 \mathrm{~m}$, only interrupted by an artificial inlet limited by two jetties that communicates it with the Mediterranean Sea named Boukhana inlet. The external hydrodynamics of this coastal area depend on the tidal regime, the littoral drift currents, and the prevailing waves. The tidal regime of the Mediterranean region is microtidal and semidiurnal, and the sea surface level changes reaching $0.35 \mathrm{~m}$ near the lagoon inlet [10].

2.2. Hydrodynamical Model. State the relative shallowness of the lagoon in relationship to its surface area and its length; inviscid shallow water equations were used to simulate sea surface elevations, current fields due to tides, and storm surge and investigate the responsible forcing mechanisms [11]. The depth-averaged approach is believed to be adequate in estuaries that are not strongly stratified; if the vertical velocity variations are limited on the evidence of density surveys, the potential contribution to the mean flow of this forcing mechanism is negligible and the fluctuations in horizontal pressure are principally due to fluctuations in water level and are therefore barotropic. The effects of the Earth's rotation are very weak due to the small dimensions of the basin, so Coriolis forcing also has not been taken into account.

Based on the simplifications described above, the primitive form of depth-integrated governing equations includes a continuity equation and momentum equation in each of the $x$ and $y$ directions which are defined as follows:

$$
\begin{aligned}
& \frac{\partial h}{\partial t}+\frac{\partial(h u)}{\partial x}+\frac{\partial(h v)}{\partial y}=0, \\
& \frac{\partial(h u)}{\partial t}+\frac{\partial\left(h u^{2}+g h^{2} / 2\right)}{\partial x}+\frac{\partial(h u v)}{\partial y} \\
& =-g h \frac{\partial Z_{b}}{\partial x}-\frac{\tau_{b x}}{\rho}+\frac{\tau_{w x}}{\rho}, \\
& \frac{\partial(h v)}{\partial t}+\frac{\partial(h v u)}{\partial x}+\frac{\partial\left(h v^{2}+g h^{2} / 2\right)}{\partial y} \\
& =-g h \frac{\partial Z_{b}}{\partial y}-\frac{\tau_{b y}}{\rho}+\frac{\tau_{w y}}{\rho},
\end{aligned}
$$

where $h$ is the water depth, $u$ and $v$ are the depth-averaged velocities in the $x$ and $y$ directions, respectively, $g$ is the gravity constant, $\rho$ is the water density, and $\tau_{b x}$ and $\tau_{b y}$ are the bed shear stress friction forces in the $x$ and $y$ directions, respectively, defined by the depth-averaged velocities:

$$
\begin{gathered}
\tau_{b x}=\rho C_{b} u \sqrt{u^{2}+v^{2}}, \\
\tau_{b x}=\rho C_{b} v \sqrt{u^{2}+v^{2}},
\end{gathered}
$$

where $C_{b}$ is the bed friction coefficient.

The surface stress $\tau_{w}$ is usually originated by the shear of the blowing wind and is expressed as a quadratic function of the wind velocity:

$$
\begin{aligned}
& \tau_{w x}=\rho_{A} C_{d} w_{x} \sqrt{w_{x}^{2}+w_{y}^{2}}, \\
& \tau_{w y}=\rho_{A} C_{d} w_{y} \sqrt{w_{x}^{2}+w_{y}^{2}},
\end{aligned}
$$

where $C_{d}$ is the coefficient of wind and $W=\left(w_{x}, w_{y}\right)^{T}$ is the velocity of wind.

2.3. Finite Volume Method. In the present study, a numerical model has been used to simulate the hydrodynamics behavior of Nador lagoon. The finite volume method is used to solve governing equations (1) discussed above, while using an unstructured triangular mesh (see Figure 2). A cell-centered finite volume method approach is used in this model, in 


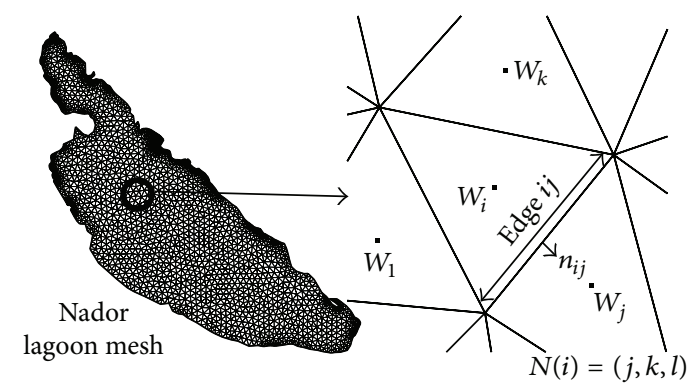

Figure 2: Nador lagoon mesh used in computational model and schematization of an example cell-centered finite volume.

which the average values of conserved variables are stored at the center of each cell with the edges of a cell defining the interface between this cell and the neighboring cells. In the current model, schemes and techniques whose robustness is widely recognized were used: especially, the Roe-MUSCL scheme for computing convective flow fluxes and Vázquez scheme for treatment of the term source. This model is initiated and developed by Elmahi et al. in [12] and refined and tested in real and complex areas by Chaabelasri et al. in [13-16].

To simplify, the above hydrodynamic equations can be written in a matrix form as follows:

$$
\partial_{t} \mathbf{U}+\partial_{x} \mathbf{F}+\partial_{y} \mathbf{G}=\mathbf{S}
$$

Herein $\mathbf{U}=(h, h u, h v)^{T}, \mathbf{F}=\left(h u, h u^{2}+0,5 g h^{2}, h u v\right)^{T}$, $\mathbf{G}=\left(h v, h u v, h v^{2}+0,5 g h^{2}, h u v\right)^{T}$, and $\mathbf{S}=\left(0,-g h \partial_{x} Z_{b}-\right.$ $\left.\left(\tau_{b x}-\tau_{w x}\right) \rho^{-1},-g h \partial_{y} Z_{b}-\left(\tau_{b y}-\tau_{w y}\right) \rho^{-1}\right)$ are the vectors that, respectively, contain the flow variables, the fluxes in the two Cartesian directions, and the source terms. In the context of triangular finite volumes, the integral around the element is written as the sum of the contributions from each edge, such that

$$
\begin{aligned}
& \frac{\mathbf{U}_{i}^{n+1}-\mathbf{U}_{i}^{n}}{\Delta t}\left|V_{i}\right|+\sum_{j \in N(i)} \int_{\Gamma_{i j}} \mathscr{F}\left(\mathbf{U}^{n}, \mathbf{n}\right) d \Gamma \\
& =\sum_{j \in N(i)} \int_{\Gamma_{i j}} \mathbf{S}\left(\mathbf{U}^{n}, \mathbf{n}\right) d \Gamma,
\end{aligned}
$$

where $\mathbf{U}^{n}$ is the vector of conserved variables evaluated at time level $t^{n}=n \Delta t, n$ is the number of time steps, $\Delta t$ is the time step, $\Gamma_{i j}$ is $i$ - $j$ edge, $N(i)$ is set of neighboring triangles of cell $i,\left|V_{i}\right|$ is the area of cell $V_{i}$, and $\mathbf{n}$ is unit vector normal to $\Gamma_{i j}$ pointing towards cell $V_{j}$. To evaluate the state $\mathbf{U}^{n+1}$, an approximation is required of the convective flux terms at each edge of the cell. To evaluate the integral along the $i$ - $j$ edge of a control volume of the normal flux $\mathscr{F}\left(\mathbf{U}^{n}, \mathbf{n}\right)=\mathbf{F} n_{x}+\mathbf{G} n_{y}$ an upwind scheme based on Roe's approximate Riemann solver is employed [14, 17-19]. At each cell edge the normal flux is as follows:

$$
\begin{array}{rl}
\int_{\Gamma_{i j}} & \mathscr{F}\left(\mathbf{U}^{n}, \mathbf{n}\right) d \Gamma \\
= & \frac{1}{2}\left\{\mathscr{F}\left(\mathbf{U}_{i}, \mathbf{n}_{i j}\right)+\mathscr{F}\left(\mathbf{U}_{j}, \mathbf{n}_{j i}\right)\right\} \cdot L_{i j} \\
& -\frac{1}{2}\left\{R\left(\overline{\mathbf{U}}, \mathbf{n}_{i j}\right)\left|\mathbf{A}\left(\overline{\mathbf{U}}, \mathbf{n}_{i j}\right)\right| L\left(\overline{\mathbf{U}}, \mathbf{n}_{i j}\right) \cdot\left(\mathbf{U}_{i}-\mathbf{U}_{j}\right)\right\} \\
& \cdot L_{i j},
\end{array}
$$

where $R$ and $L$ are the right and left eigenvector matrices of the flux Jacobian evaluated using Roe's average state $\overline{\mathbf{U}}$ and $|\mathbf{A}|$ is a diagonal matrix of the absolute values of the eigenvector of the flux Jacobian matrix [14].

The evaluation of source terms in (5) is carried out such that the discretization of the source term is well balanced with the discretization of flux gradients using the concept of Cproperty [20]. The upwinded approximation of source term replaced by numerical source vector is given by

$$
\begin{aligned}
\int_{\Gamma_{i j}} \mathbf{S}\left(\mathbf{U}^{n}, \mathbf{n}\right) d \Gamma= & \left\{\mathbf{I}-\left|\mathbf{A}\left(\overline{\mathbf{U}}, \mathbf{n}_{i j}\right)\right| \mathbf{A}\left(\overline{\mathbf{U}}, \mathbf{n}_{i j}\right)\right\} \\
& \cdot \mathbf{S}^{n}\left(\mathbf{X}_{i}, \mathbf{X}_{j}, \mathbf{U}_{i}, \mathbf{U}_{j}, \mathbf{n}_{i j}\right) \cdot L_{i j},
\end{aligned}
$$

where $\mathbf{I}$ is the identity matrix, $\mathbf{A}\left(\overline{\mathbf{U}}, \mathbf{n}_{i j}\right)$ is the Roe flux Jacobian, and $S^{n}$ represents an approximation of the source term on the cell interface. Once more we refer to [14] for more details about used numerical schemes.

Finally, the stability criterion adopted has followed the usual in explicit finite volumes; the time step is set according to the Courant-Friedrichs-Lewy (CFL) criterion equal to 0.65 .

2.4. Numerical Setup. The numerical computation has been carried out on a spatial domain that represents the lagoon of Nador through a finite volume grid which consists of 8075 triangular elements and 14042 nodes. The bathymetry of the lagoon, obtained by combining several data sets, has been interpolated onto the grid. The finite volume method allows for high flexibility with its subdivision of the numerical domain in triangles varying in form and size. It is especially suited to reproduce the geometry and the hydrodynamics of complex shallow water basins such as the Nador lagoon. The principal hydraulic forcing of the Nador lagoon is the tide and the wind. The main astronomical tidal constituents in this lagoon are semidiurnal $M_{2}, S_{2}$, and $N_{2}$ tides [21]

$$
h(t)=h(t=0)+\sum_{i} A_{i} \cos \left(\omega_{i} t+\phi_{i}\right)
$$

where $A_{K}$ is the wave amplitude the angular frequency and the tide phase of $K$ th tidal constituent, noting that $K, K=$ $M_{2}, S_{2}, N_{2}$. In this model, the boundary condition is the fact that always no drying case is considered and the tide has been imposed at the beginning of the main inlet. 


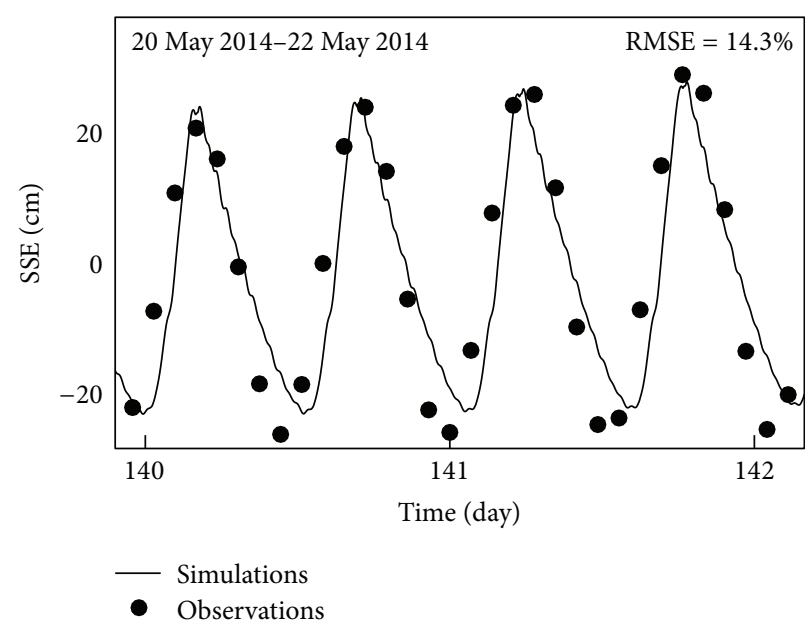

(a)

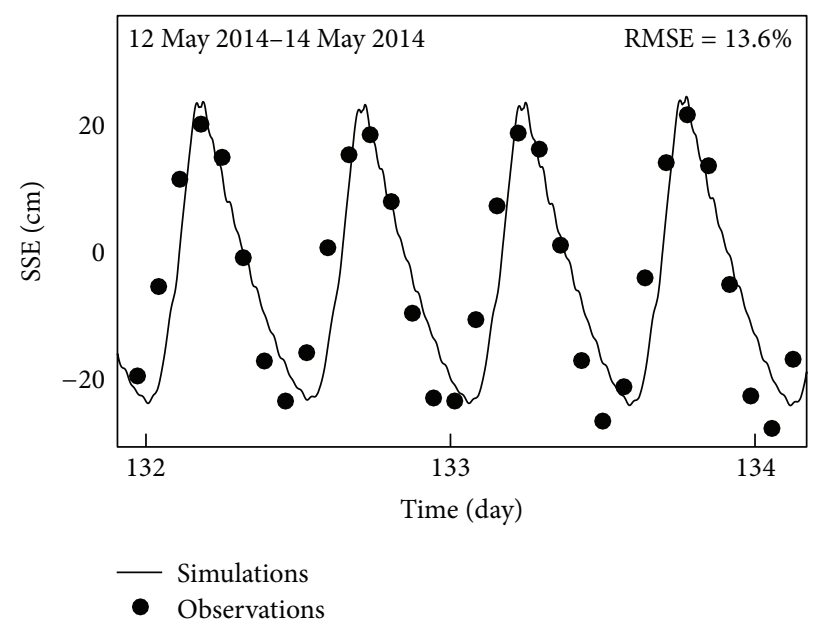

(b)

Figure 3: Predicted and observed SSE versus time for validation (b) and verification (a) period.

Using the numerical model must begin with calibration and verification by means of adjusting Manning's roughness coefficient. This strategy was done using tidal flow at the inlet, extrapolated from harmonic analysis of measured flow in Beni-Ensar harbour, for two days (approximately four tidal cycles). One set of data (12 to 14 May 2014) was used for model calibration and another separate set (20 to 22 May 2014) for model verification. Typical predicted and observed values for sea surface elevation SSE versus time are presented in Figure 3 showing a success agreement. Moreover, calculated RMSE for both cases is less than $14 \%$.

\section{Results and Discussions}

In order to achieve a stable time-periodic solution, the model was run for further 5 days, forced by $M_{2}, S_{2}$, and $\mathrm{N}_{2}$ semidiurnal tidal components. After reaching the stable time-periodic regime, experiments were carried out for three scenarios of a typical tidal cycle with different wind forcing. Firstly, we analyzed the calm case. Then, western and eastern wind forcing cases are considered. In each instance, we treated the wind as steady and homogeneous to show the resulting water circulation.

Table 1 summarizes the parameters used in simulation runs.

3.1. Tide Currents Speed and Elevation. In the first case only the tidal forcing is considered and no wind is prescribed. The numerical simulations are presented in Figure 4 that shows four snapshot states of the sea surface level in Nador lagoon corresponding to one typical period. Significant changes in sea surface level are confined to the local area of lagoon. The value of sea surface elevation is reduced significantly greatly near the inlet and reduced inside the lagoon. The values oscillate from a maximum of $70 \mathrm{~cm}$ to a minimum of $-20 \mathrm{~cm}$ compared to reference state, during the selected typical tidal, without exceeding a difference of approximately $10 \mathrm{~cm}$ between the maximum and minimum height in each
TABLE 1: Parameters of the hydrodynamic model.

\begin{tabular}{lcc}
\hline Parameter & Symbol & Value \\
\hline Time step & $\Delta t$ & $\simeq 3 \mathrm{~s}$ \\
Water density & $\rho_{w}$ & $1025 \mathrm{Kg} \cdot \mathrm{m}^{-3}$ \\
Air density & $\rho_{A}$ & $1.225 \mathrm{Kg} \cdot \mathrm{m}^{-3}$ \\
Wind drag coefficient & $C_{d}$ & $1.14 \cdot 10^{-3} \mathrm{~m} \cdot \mathrm{s}^{-1}$ \\
\hline
\end{tabular}

measure. Hence, it can be concluded that the tidal forcing at inlet is able to induce sea surface level oscillations within the lagoon. The water exchange between lagoon and ocean should be mostly produced by this level of oscillations.

To quantify the speed spreading of the waves and more behavior understanding, velocity fields and their magnitudes are presented for the hole basin in Figure 5. Also, a time series of computed current velocity at Boukhana inlet in one typical tidal period are presented in Figure 6. It is clear that the flow speeds are great near the inlet and in the inside of the lagoon, the speeds are reduced during the tidal cycle, and the great circulation is formed. Tidal gradients at the inlet set up high tidal currents, reaching about $\left(2,2-2.4 \mathrm{~ms}^{-1}\right)$ and (1, $5-2 \mathrm{~ms}^{-1}$ ) in the flood and ebb time, respectively, at the inlet which decrease progressively along the south/north shores of the lagoon. Further, the circulation comprises three principal gyres, the sense of gyres is both cyclonic and anticyclonic, and also other small gyres are distributed far in inlet in the edge, in the southeast and in the northwest of the lagoon. Physically, these gyres are the consequence of the cooscillations with tidal waves propagation in the neighboring sea or ocean and to rapid dissipation of the tidal energy.

From environmental viewpoint, certainly, the spatial variability in water circulation was controlled by the intricate geometry of the lagoon, which influences and modifies the current pattern, but also, this result shows a relation to the current tide structure which, during the period analyzed, was controlled by sea water. The spatial variability of water circulation has a noticeable influence in the risk assessment of 

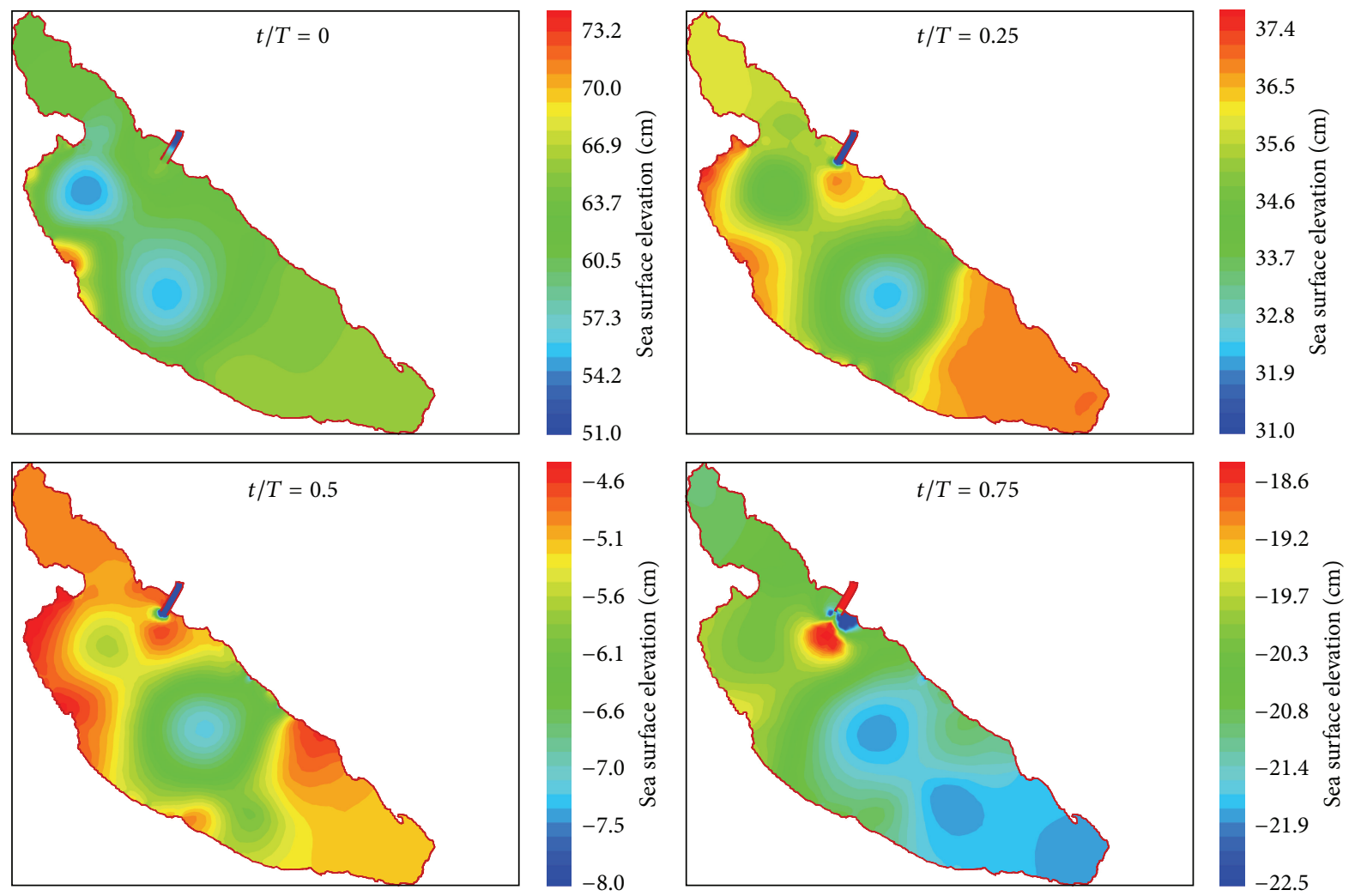

FIGURE 4: Time sea surface level in Nador lagoon during a typical period.
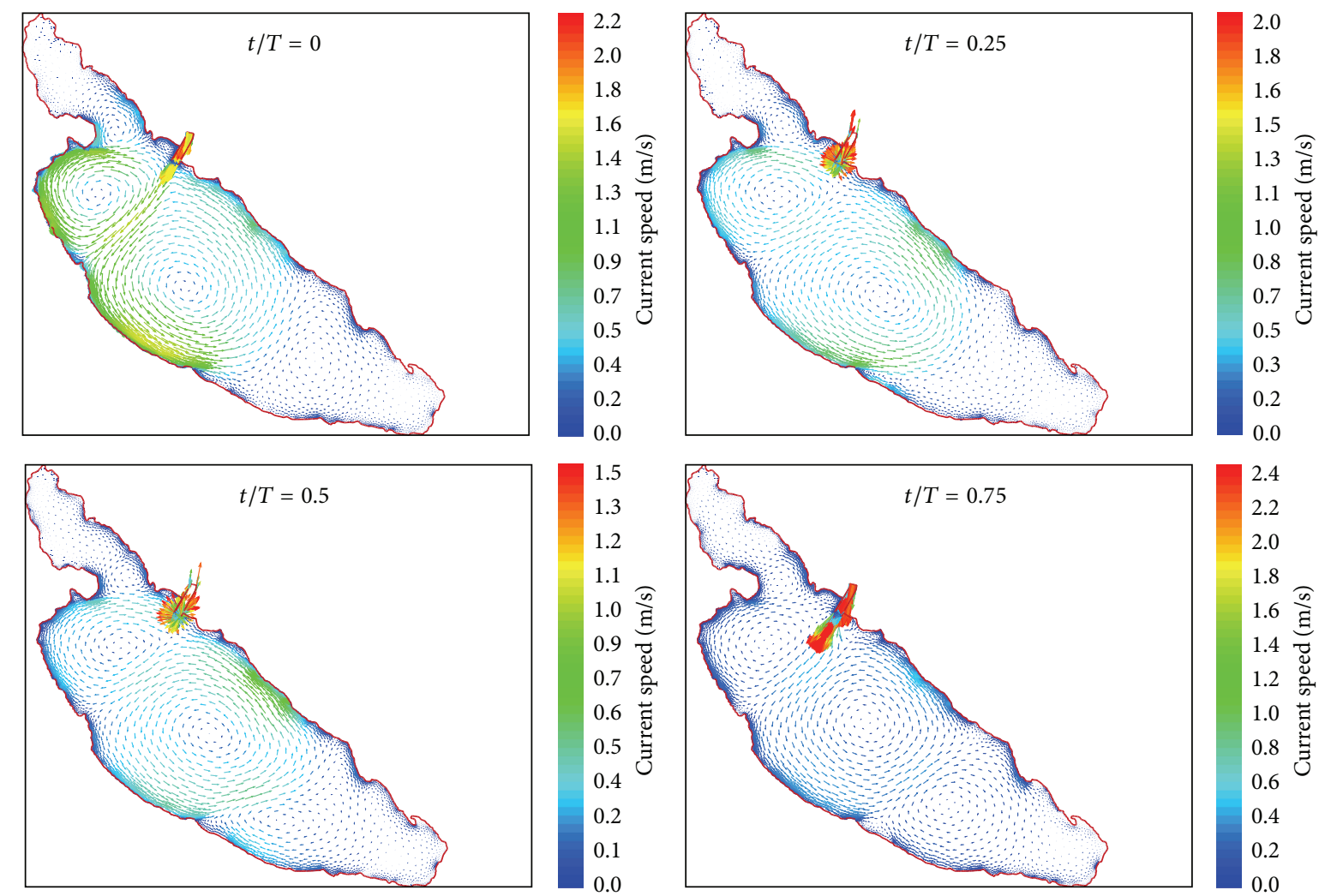

FIGURE 5: Velocity fields and magnitudes corresponding to those in Figure 4. 


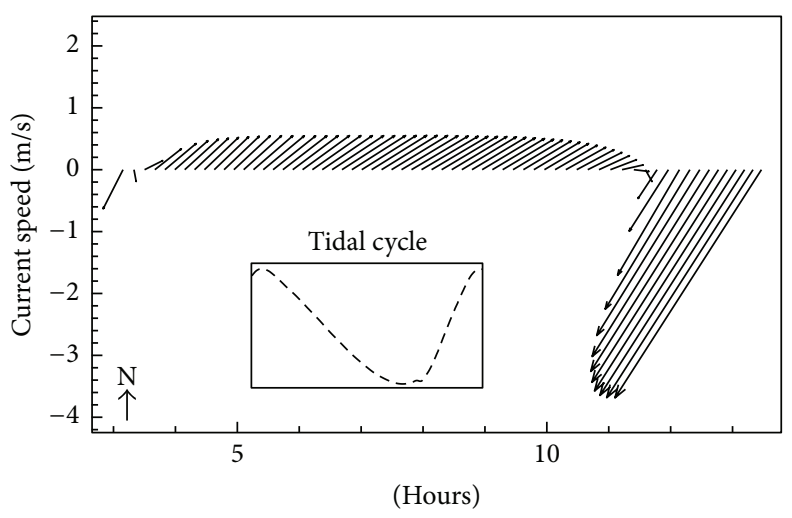

FIGURE 6: Time series of computed current velocity (top) at Boukhana inlet in a typical tidal period.
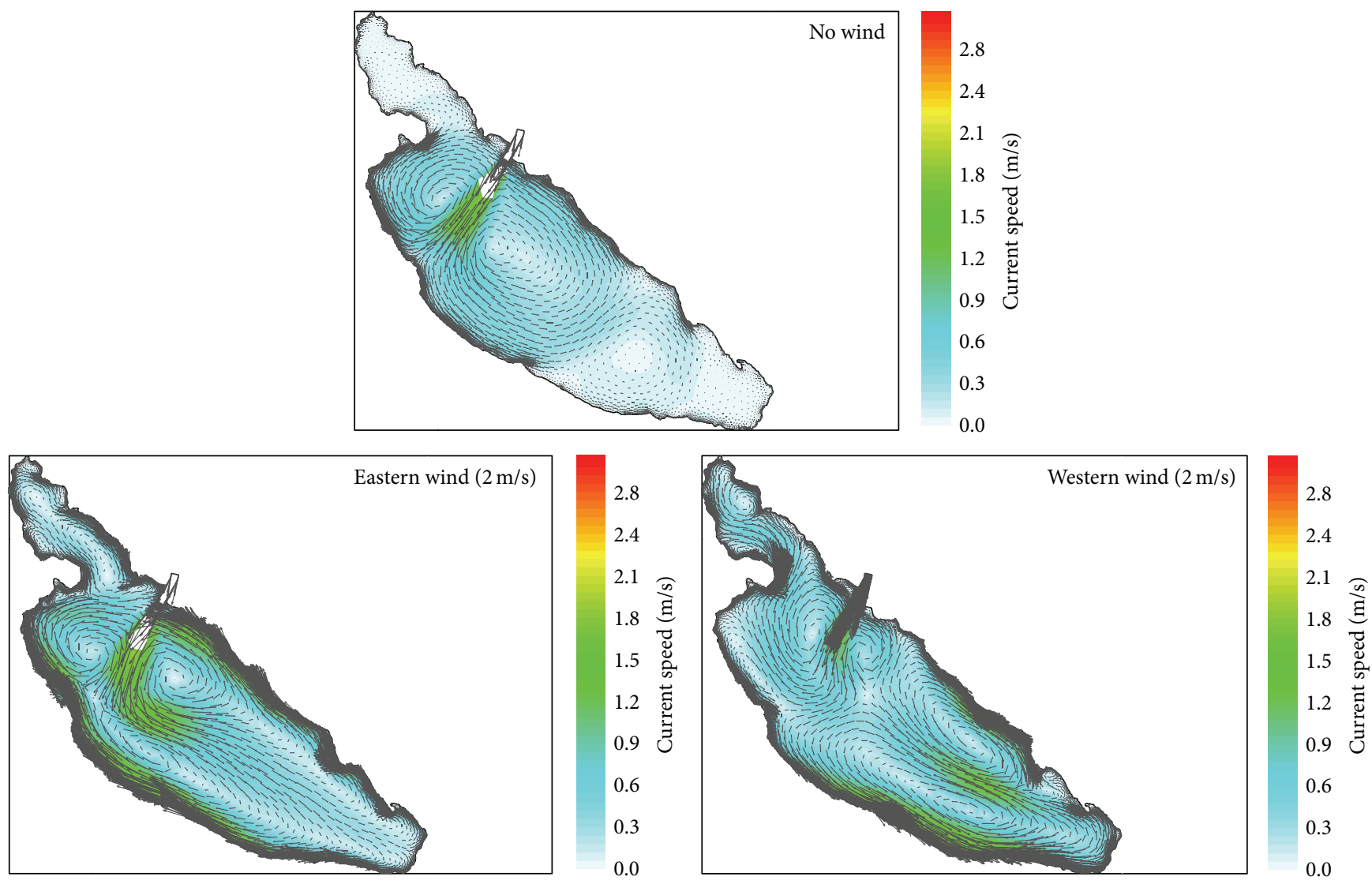

FIGURE 7: Comparison of velocity fields and magnitudes in Nador lagoon for the wind cases.

water pollution in the lagoon. Thus, careful characterization of water renewal is necessary, in order to implement a methodology of risk assessment for environmental management.

3.2. Tide and Wind Induced Circulation. In this study, the wind is imposed from the east on one hand and the west on the other hand. Its intensity is $2 \mathrm{~m} / \mathrm{s}^{-1}$. When the tidal forcing is supplemented by the wind action, the lagoon circulation changes radically. Figure 7 represents a numerical comparison of current speed between the no wind case and wind cases. The most noticeable lagoon response to the northeast wind forcing was the deformation of numerous permanent circulations in different areas of the lagoon according to the sense of wind direction. Moreover, the wind affects the whole lagoon surface and is capable of inducing some gyres formation in the central and northern sectors. These gyres rotate in a clockwise direction and are connected to each other. Hence, it can be concluded that the gyres are formed because of the depth gradient in these regions, implying that bottom topography plays an important role in determining the circulation within the main body of the lagoon local water 
movements. Still, this does not imply water exchange with the sea.

\section{Conclusion}

This paper has presented the application of comprehensive hydrodynamic numerical procedure, specifically conceived for shallow water modelling, to the Nador lagoon. Through this numerical model, simulations of the effect of tide and wind on water current of the lagoon are carried out. The numerical results show correct physics in different test regimes. The influence of different winds forcing on the water circulation has also been discussed. Nevertheless, flows in such complex domains can be computed, providing correct physics without the need for generating adaptive grids or complicated reconstruction of numerical fluxes. Overall, the method shows reasonable accuracy while ensuring the required properties of the shallow water flows. Finally, much more efforts are required. The model calibration with experimental or observed data will be a challenge for future studies.

\section{Symbols}

\begin{tabular}{|c|c|}
\hline$h:$ & $\begin{array}{l}\text { Total depth from the sea bed to the free } \\
\text { surface }(\mathrm{m})\end{array}$ \\
\hline$u, v:$ & $\begin{array}{l}\text { Cartesian components of depth-averaged } \\
\text { velocity }(\mathrm{m} / \mathrm{s})\end{array}$ \\
\hline$Z_{b}:$ & $\begin{array}{l}\text { Bed elevation above a fixed horizontal } \\
\text { datum }(\mathrm{m})\end{array}$ \\
\hline$g:$ & Acceleration due to gravity $\left(\mathrm{m} / \mathrm{s}^{2}\right)$ \\
\hline$\rho:$ & Water density $\left(\mathrm{kg} / \mathrm{m}^{3}\right)$ \\
\hline$\rho_{A}:$ & Air density $\left(\mathrm{kg} / \mathrm{m}^{3}\right)$ \\
\hline$W_{x}, W_{y}:$ & Components of wind speed $(\mathrm{m} / \mathrm{s})$ \\
\hline$\tau_{b, x}, \tau_{b, y}:$ & Bed shear stress components \\
\hline$\tau_{w, x}, \tau_{w, y}:$ & Free surface shear stress components \\
\hline$C_{b}:$ & Bed friction coefficient \\
\hline$C_{d}:$ & Wind drag coefficient \\
\hline$t:$ & Time $(s)$ \\
\hline$x, y:$ & $\begin{array}{l}\text { Cartesian horizontal distances from } \\
\text { origin. }\end{array}$ \\
\hline
\end{tabular}

\section{Conflict of Interests}

The authors declare that there is no conflict of interests regarding the publication of this paper.

\section{References}

[1] K. Bloundi and J. Duplay, "Heavy metals distribution in sediments of Nador lagoon (Morocco)," Geophysical Research Abstracts, vol. 5, Article ID 11744, 2003.

[2] F. Ruiz, M. Abad, M. Olías et al., "The present environmental scenario of the Nador Lagoon (Morocco)," Environmental Research, vol. 102, no. 2, pp. 215-229, 2006.

[3] A. Lefebvre, O. Guelorget, J. P. Perthuisot, and J. E. Dafire, "Biogeological evolution of the lagoon of Nador (Morocco) during the period 1982-1993," Oceanolica Acta, vol. 20, no. 2, pp. 371-385, 1996.
[4] O. Kada, Biological and ecological study of the Moroccan Mediterranean anchovies and characterization of lagoon populations (Nador lagoon) [Ph.D. thesis], Abdelmalek Essaâdi University, Tétouan, Morocco, 2011.

[5] I. Brenon, S. Mondé, N. Pouvreau, and J. C. Maurin, "Modeling hydrodynamics in the Ebrié Lagoon (Côte d'Ivoire)," Journal of African Earth Sciences, vol. 39, no. 3-5, pp. 535-540, 2004.

[6] C. Ferrarin, G. Umgiesser, M. Bajo et al., "Hydraulic zonation of the lagoons of Marano and Grado, Italy. A modelling approach," Estuarine, Coastal and Shelf Science, vol. 87, no. 4, pp. 561-572, 2010.

[7] D. Serrano, E. Ramírez-Félix, and A. Valle-Levinson, "Tidal hydrodynamics in a two-inlet coastal lagoon in the gulf of California," Continental Shelf Research, vol. 63, pp. 1-12, 2013.

[8] T. Lovato, A. Androsov, D. Romanenkov, and A. Rubino, "The tidal and wind induced hydrodynamics of the composite system Adriatic Sea/Lagoon of Venice," Continental Shelf Research, vol. 30, no. 6, pp. 692-706, 2010.

[9] U. S. Panda, P. K. Mohanty, and R. N. Samal, "Impact of tidal inlet and its geomorphological changes on lagoon environment: a numerical model study," Estuarine, Coastal and Shelf Science, vol. 116, pp. 29-40, 2013.

[10] J. C. Brethes and M. Tesson, Hydrological Observation on the Sebkha Bou-Areg Nador Lagoon (Morocco), 1978.

[11] R. A. Luettich Jr., S. D. Carr, J. V. Reynolds-Fleming, C. W. Fulcher, and J. E. McNinch, "Semi-diurnal seiching in a shallow, micro-tidal lagoonal estuary," Continental Shelf Research, vol. 22, no. 11-13, pp. 1669-1681, 2002.

[12] I. Elmahi, Schémas volumes finis pour la simulation numérique de probléme á fronts raides en maillages non structurés adaptatifs [Ph.D. thesis], Université de Rouen, Mont-Saint-Aignan, France, 1999.

[13] E. M. Chaabelasri, A. Amahmouj, and N. Salhi, "Computations of pollutant dispersion in coastal waters of Tangier's bay," International Review on Modelling and Simulations, vol. 5, no. 4, pp. 1588-1595, 2012.

[14] E. M. Chaabelasru, A. G. L. Borthwick, N. Salhi, and I. Elmahi, "Balanced adaptive simulation of pollutant transport in Bay of Tangier (Morocco)," World Journal of Modelling and Simulation, vol. 10, no. 1, pp. 3-19, 2014.

[15] F. Boushaba, E. M. Chaabelasri, N. Salhi, I. Elmahi, F. Benkhaldoun, and A. G. L. Borthwick, "A comparative study of finite volume and finite element on some transcritical free surface flow problems," International Journal of Computational Methods, vol. 5, no. 3, pp. 413-431, 2008.

[16] M. Jeyar, E. M. Chaabelasri, and N. Salhi, "Numerical investigation of new alternative Nador lagoon inlet relocation," International Journal of Fluid Mechanics Research, vol. 5, no. 3, pp. 449-462, 2015.

[17] F. Alcrudo, P. Garcia-Navarro, and J.-M. Saviron, "Flux difference splitting for 1D open channel flow equations," International Journal for Numerical Methods in Fluids, vol. 14, no. 9, pp. 10091018, 1992.

[18] Ch. Hirsh, Numerical Computation of Internal and External Flows: The Fundamentals of Computational Uid Dynamics, vol. 1, Wiley and Sons, 2nd edition, 2007.

[19] M. E. Vázquez-Cendón, "Improved treatment of source terms in upwind schemes for shallow water equations in channels with irregular geometry," Journal of Computational Physics, vol. 148, no. 2, pp. 497-526, 1999. 
[20] A. Bermudez and M. E. Vazquez, "Upwind methods for hyperbolic conservation laws with source terms," Computers and Fluids, vol. 23, no. 8, pp. 1049-1071, 1994.

[21] M. K. Banda and M. Seaid, "Lattice Boltzmann simulation for shallow water flow applications," in Hydrodynamics-Theory and Model, J. Zheng, Ed., chapter 11, InTech, Rijeka, Croatia, 2005. 

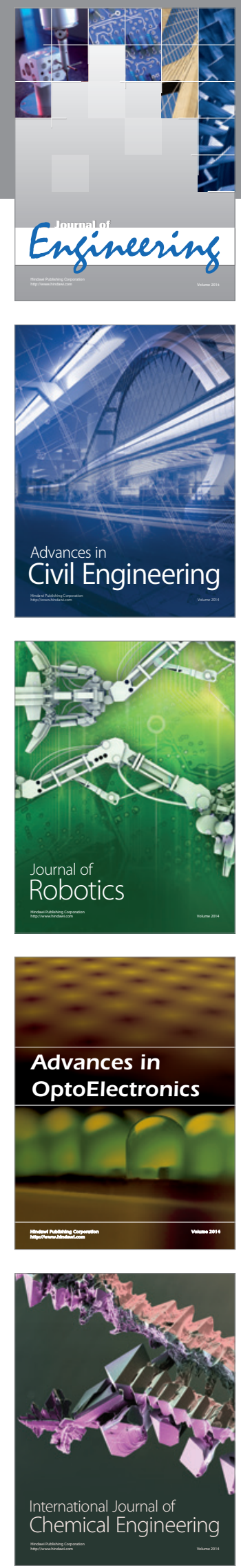

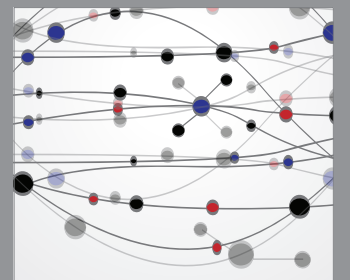

The Scientific World Journal
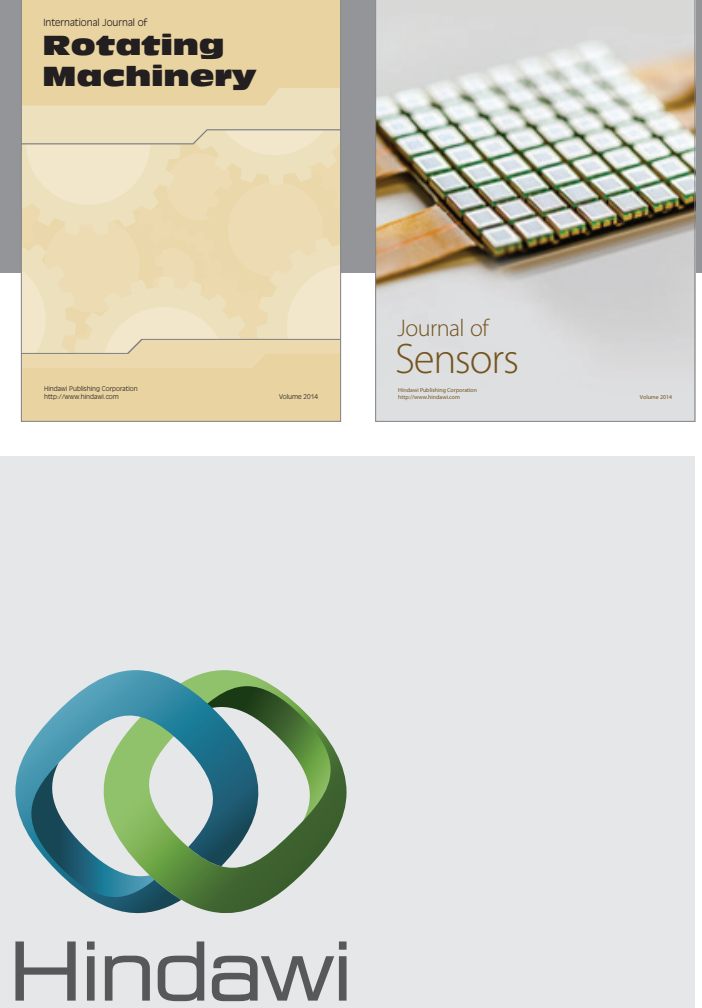

Submit your manuscripts at http://www.hindawi.com
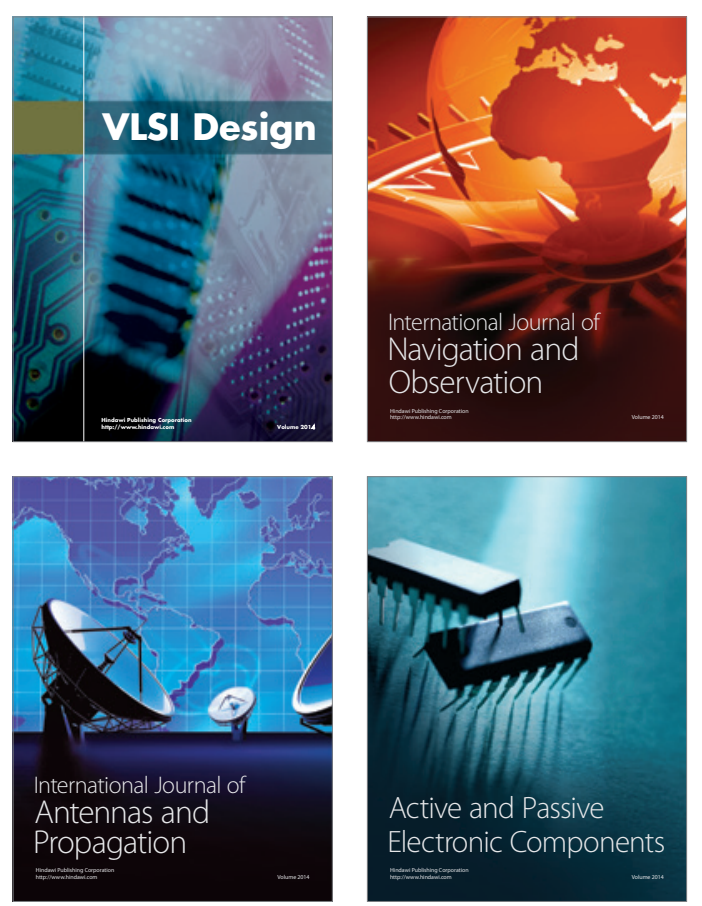
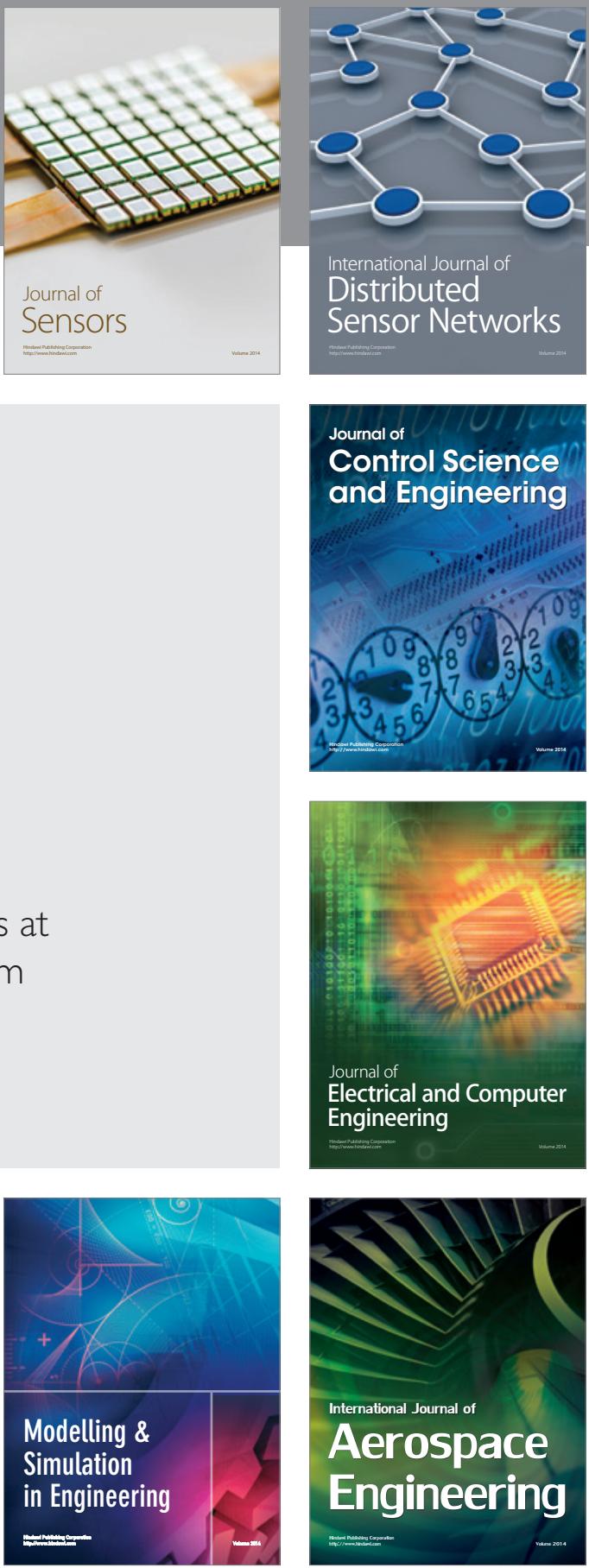

Journal of

Control Science

and Engineering
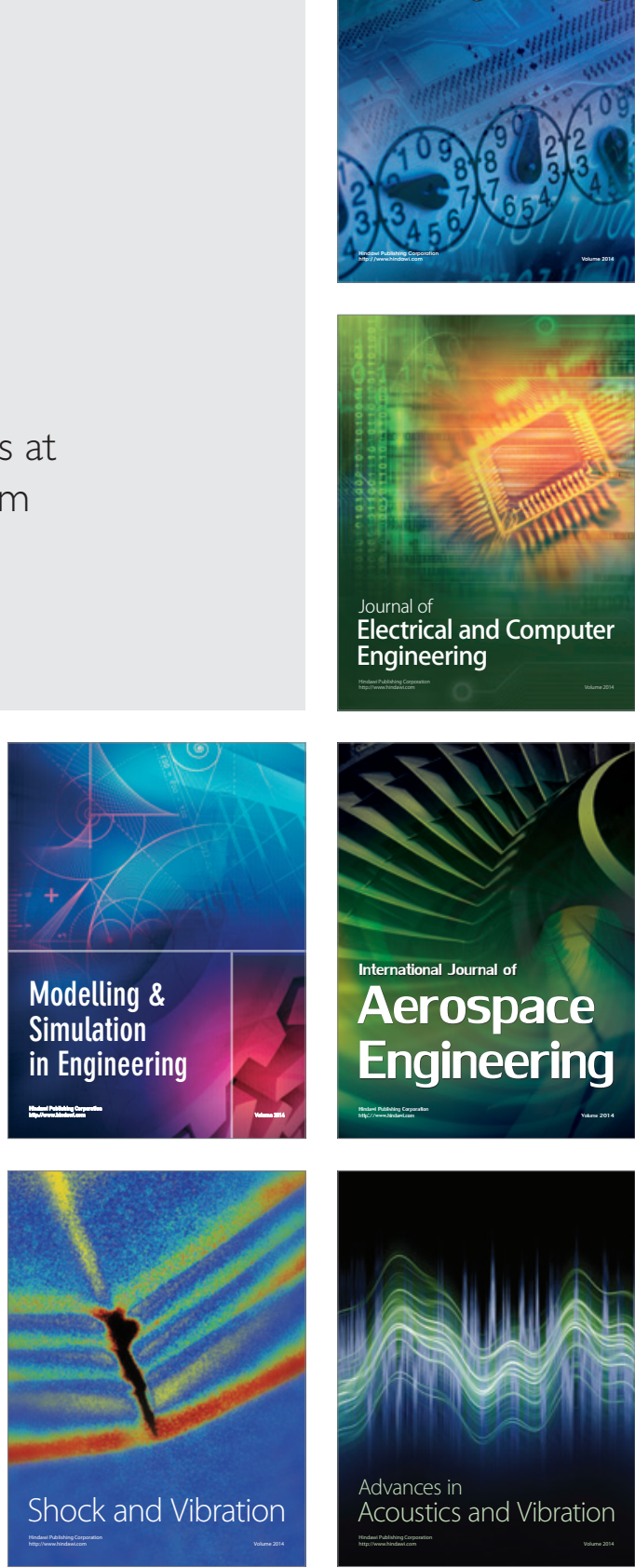